\title{
Fournier Gangrene Severity Index and Diabetes Mellitus: A Significance Correlation among Fournier Gangrene Patients in Single Center Hospital
}

\author{
Hanum Faeni ${ }^{1 *}$, Wibisono Wibisono ${ }^{2}$, Galih Santosa Putra ${ }^{1}$, Muhammad David Perdana Putra ${ }^{1}$ \\ ${ }^{1}$ Department of Surgery, Universitas Sebelas Maret, Surakarta, Central Java, Indonesia; ${ }^{2}$ Department of Urology, Universitas \\ Sebelas Maret, Surakarta, Central Java, Indonesia
}

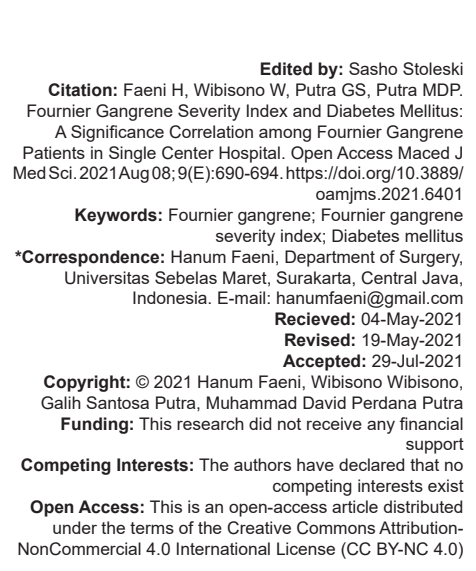

Introduction

Fournier gangrene $(F G)$ is one of the urology emergencies in the form of progressive necrotizing fascitis caused by polymicrobial infection which attacks the perineum and external genitalia. FG that is not diagnosed and treated properly will result in severe morbidity and even mortality for the patient. This disease affects older people who are mostly aged 50 and 60 years with various basic diseases, in which diabetes mellitus (DM) is the most comorbid $(50-70 \%)$. Polymicrobials that cause the progression of this disease, necessitating aggressive, immediate surgery (debridement), and appropriate medical therapy.

It was reported that the incidence of FG in the general population was $1: 7,500$ and $1-2 \%$ were treated by a urologist at the hospital. A retrospective study in Korea found 1726 cases from 1950 to 1999 and an average of 97 cases per year were reported, from 1989 to 1998.

FG is more common in elderly male patients, ten percent can affect women (male to female ratio $10: 1$ ). The age of the FG patients was $30-60$ years with a peak incidence of 5 and 6 years. In previous studies, it was reported that the mean age of FG patients in 1945 was 40.9 years, 1979 (Jones) was 51.3 years, Laor and colleagues were 61 years.

$D M$ is the most comorbid in FG patients $(50-70 \%)$ and is associated with poor outcome and increased mortality by $25 \%$ (3 of 12 patients) [1], [2].

The organisms that cause FG can be found in necrotic tissue, pus swabs, blood, or urine cultures. FG is caused by aerobic and anaerobic polymicrobial infection that causes vascular thrombosis and necrotic tissue, exacerbated by low body defense due to other underlying diseases. 
The diagnosis of $F G$ is made on the basis of clinical examination. There are complaints such as fever, weakness, nausea and vomiting, perineal discomfort, uncontrolled blood glucose. The period lasts from 2 to 9 days. The discomfort in the genitalia and perineal will get worse, along with pain, itching, burning sensation, erythema, swelling, and even skin necrosis. The wound can produce bad-smelling pus. The pain will subside when neuron damage has occurred. The presence of crepitus can be difficult to examine because of pain on palpation, but it is present in $50-60 \%$ of cases [1], [3], [4], [5].

The clinical picture of FG can be seen as follows (Figure 1).

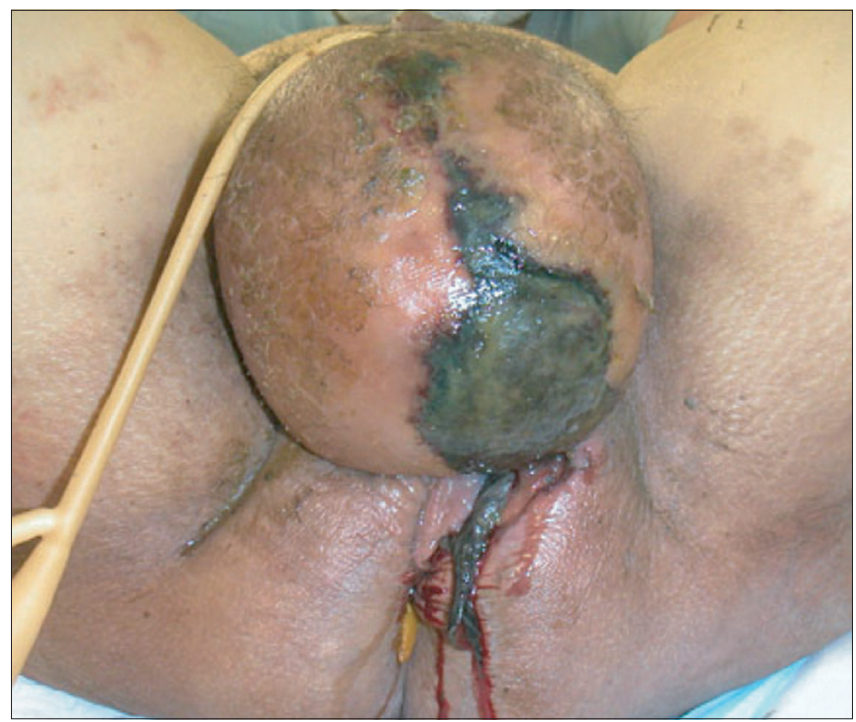

Figure 1: Necrotic Area in Fournier Gangrene

(Source: Wein et al., Campbell Walsh Urology, Fournier Ganggrene, $10^{\text {th }}$ edition, 2012)

Clinical signs such as elevated body temperature, tachycardia, tachipnea, ileus, uncontrolled blood sugar, and the discovery of vascular problems, but these are not always present, especially in patients with immunosuppressive disorders.

Once there is necrosis of the skin, there will be extensive necrosis. Complaints and clinical symptoms depend on the origin of the infection. History of complaints in the lower urinary tract, indicating urethral stricture. Anorectal complaints such as pain, fissure ani, or hemorrhoids indicate the source of FG infection is anorectal. Therefore we need a scoring system to predict the severity of the morbidity of FG so that there is no misssed or delay in diagnosis [1], [3], [4], [5].

Management of FG with aggressive synergistic resuscitation with anticipated surgery, airway management, administration of oxygen, intravenous access, administration of crystalloid fluids, especially patients with dehydration or signs of shock, and cardiological monitoring.

Administration of broad-spectrum antibiotics for gram-positive, negative, aerobic, and anaerobic bacteria, such as Ampicillin-sulbactam, Ticarcillin-Clavulanate, Piperacillin/tazobactam, Penicillinase, aminoglycosides, metronidazole, or clindamycin. Administration of Vancomycin, especially for MRSA [1], [4], [6].

Tetanus prophylaxis is administrated if soft tissue injury was indicated. Consultation with a surgeon is very important, especially to urologists and colorectal consultants [1], [4], [6].

Immediate and aggressive debridement has a positive effect on patient survival (reduces patient morbidity and mortality). This operative action should be performed under general anesthesia, where the actual wound is usually more severe than it appears. The patient is positioned in the dorsal lithotomy position. The goal of debridement is to remove the origin of the site of infection as well as to remove infected tissue. Surgeons should immediately prepare their patients for radical debridement [1], [3], [4], [7], [8].

Figure 2

Adequate debridement is shown in the

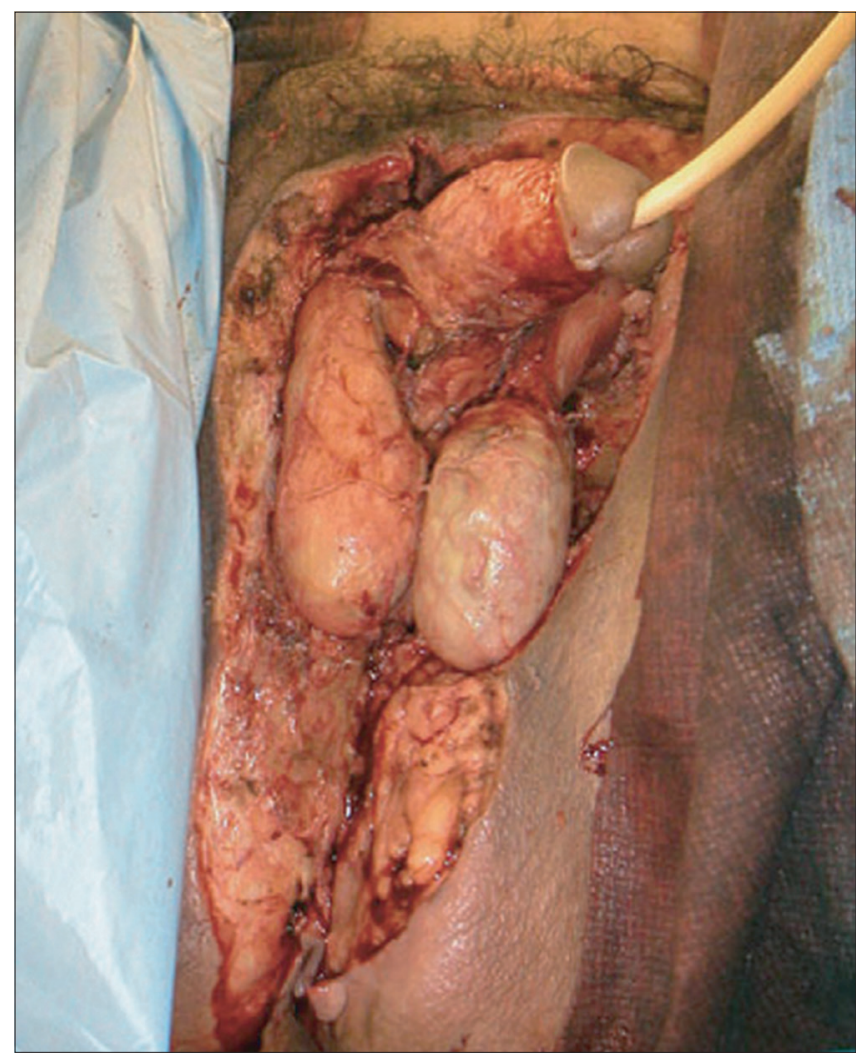

Figure 2: Adequate Debridement Results

(Source: Wein et al., Campbell Walsh Urology, Fournier Ganggrene, $10^{\text {th }}$ edition, 2012)

FG assessment becomes clearer with the creation of a scoring system that predicts patient prognostic and therapeutic outcomes, known as the FG severity index (FGSI). This FGSI includes clinical and laboratory examinations, namely, temperature, pulse, respiratory rate, levels of sodium, potassium, leukocytes, hematocrit, and blood serum bicarbonate.

FGSI is used to predict the prognostic outcome of FG patients. Temperature, pulse, respiratory rate, and 
leukocytes are the criteria for sepsis. Disorders of the balance of levels of sodium, potassium, serum bicarbonate and creatinine indicate metabolic disturbances, while hematocrit indicates an infection/inflammatory process. The infection process can result in sepsis and metabolic disorders of the body so that the FGSI parameter can predict the bad risk of FG patients [6], [9].

The Table 1 shows the FGSI parameters and their numerical scores, with normal values and abnormal values.

FGSI score assessment is done by adding up each score of each parameter. The total FGSI score is divided into 2 values, namely, an FGSI value of $<9$ and more than 9. FGSI above 9 is considered to have sensitivity and specificity to FG patient mortality. Sorensen et al. also reported that if the FGSI is above 9 then the probability of mortality is $75 \%$, if it is below 9 the chance of survival is $78 \%$ with a mortality rate of $12.12 \%$ [6], [9], [10], [11]

\section{Methods}

This retrospective study was descriptive, which examined the relationship between age and DM with FGSI in FG patients at the Regional General Hospital dr. Moewardi Surakarta (RSDM) for the period January 2017 - December 2020.

Data was taken from January 2017 to December 2020 at the Urology department of the Regional General Hospital dr. Moewardi Surakarta. The study population was patients with a diagnosis of FG who were admitted to the surgical emergency department, consulted from other departments, or were treated in the Urology subsection of the RSDM from January 2017 to December 2020. There were 32 cases of FG patients, consisting of 20 patients with DM and 12 non-DM patients.

\section{Results}

This study found a study population of 40 patients with a diagnosis of FG, but only 32 FG patients met the study inclusion criteria within 3 years from January 2017 to December 2020. The distribution of FG patients based on age, most of them were aged $50-59$ years with 16 patients $50 \%$ ), followed by the age of 60-69 years with 11 patients (34.37\%), 2 patients less than 50 years of age $(6.25 \%), 2$ patients aged $70-79$ years $(6.25 \%)$ and more of 80 years 1 patient (3.13\%).

In this study, the age distribution of FG patients with FGSI scores was divided into two groups, namely, scores $<9$ and scores more than 9 , as shown in the following Tables 2 and 3, there were 24 patients with FGSI scores $<9(75 \%)$, whereas FG patients with an FGSI score of $>9$ were 8 patients $(25 \%)$.

Patients with FGSI scores $<9$ were mostly at the age of 50-59 years, namely 12 patients $(37.5 \%)$, followed by the group of patients aged 60-69 years and 70-79 years with a total of 4 patients each (12.25\%), then in the age group $<50$ years and more than 80 years with a number of each of 2 patients $(6.25 \%)$.

Patients with an FGSI score of more than 9 were found in the 50-59 years and 60-69 years age groupun with the number of each 5 patients $(15.62 \%)$, followed by the age of $<50$ years, namely 2 patients $(6.25 \%)$. Patients with an FGSI score $>9$ were absent in the age group over 70 years.

Distribution of FGSI scores according to age of FG patients. Patients with an FGSI score of more than 9 were $50 \%$ at $<50$ years old, $22.2 \%$ at $50-59$ years old, $27.3 \%$ at $60-69$ years old, and $0.0 \%$ or none at each. Aged $70-79$ years and $>80$ years. This distribution is less able to indicate a certain trend.

Statistical test using the Chi-square technique resulted in the number $p=0.045$. In other words, it can be concluded that there is a significant relationship between the age of the FG patient and the FGSI score.

There were 20 patients with comorbid DM $(62.5 \%)$ while 12 patients $(37.5 \%)$ had no comorbid DM. More DM co-morbidities (62.5\%) than non-DM patients $(37.5 \%)$.

Patients with DM comorbid had an FGSI score of $<9$ in 11 patients, an FGSI score of $>9$ there were nine patients. There were seven patients without DM comorbid who had an FGSI score of $<9$ and there were no patients with an FGSI score of $>9$.

The Table 3 shows the distribution of the FGSI score according to the DM comorbid. Patients with FGSI

Table 1: FGS

\begin{tabular}{|c|c|c|c|c|c|c|c|c|c|}
\hline Variable & Abnor & igh value & & & Normal value & Abnorma & value & & \\
\hline Score & $4+$ & $3+$ & $2+$ & $1+$ & 0 & $1+$ & $2+$ & $3+$ & $4+$ \\
\hline Temperature $\left({ }^{\circ} \mathrm{C}\right)$ & $>41$ & $39-40.9$ & - & $38.5-38.9$ & $36-38.4$ & $34-35.9$ & $32-33.9$ & $30-31.9$ & $<29.9$ \\
\hline Pulse & $>180$ & $140-179$ & $110-139$ & - & $70-109$ & - & $56-59$ & $40-54$ & $<39$ \\
\hline Respiration rate & $>50$ & $35-49$ & - & $25-34$ & $12-24$ & $10-11$ & $6-9$ & - & $<5$ \\
\hline Sodium (mmol/L) & $>180$ & 160-179 & 155-159 & $150-154$ & $130-149$ & - & $120-129$ & $110-119$ & $<110$ \\
\hline Potassium (mmol/L) & $>7$ & $6-6,9$ & - & $5.5-5.9$ & $3.5-5.4$ & $3-3.4$ & $2.5-2.9$ & - & $<2.5$ \\
\hline Creatinine $(\mathrm{mg} / 100 \mathrm{~mL})$ & $>3.5$ & $2-3.4$ & $1.5-1.9$ & - & $0.6-1.4$ & - & $<0.6$ & - & - \\
\hline Hematocrit (\%) & $>60$ & - & $50-59.9$ & $46-49$ & $30-45.9$ & - & $20-29.9$ & - & $<20$ \\
\hline Leukocytes $\left(\right.$ total $\left./ \mathrm{mm}^{2} \times 1.000\right)$ & $>40$ & - & $20-39.9$ & $15-19.9$ & $3-14.9$ & - & $1-2.9$ & - & $<1$ \\
\hline Serum bicarbonate $(\mathrm{mmol} / \mathrm{L})$ & $>52$ & $41-51.9$ & - & $32-40.9$ & $22-31.9$ & - & $18-21.9$ & $15-17.9$ & $<15$ \\
\hline
\end{tabular}


Table 2: Distribution of FGSI scores by age

\begin{tabular}{llll}
\hline Age (years) & \multicolumn{2}{l}{ FGSI score $(\%)$} & M \\
\cline { 2 - 3 } & $<9$ & $1(50.0)$ & 0.045 \\
\hline$<50$ & $1(50.0)$ & $4(25)$ & \\
$50-59$ & $12(75)$ & $3(27.3)$ & \\
$60-69$ & $8(72.7)$ & $0(0.0)$ & \\
$70-79$ & $2(100.0)$ & $0(0.0)$ & \\
$>80$ & $1(100.0)$ & &
\end{tabular}

score of $>9$ were $45 \%$ in patients with DM comorbid and $0.0 \%$ or none in patients without DM comorbid. This distribution shows that patients with DM comorbid are more likely to have an FGSI score of $>9$ than patients without DM comorbid.

Table 3: Distribution of FGSI scores according to DM comorbid

\begin{tabular}{llll}
\hline Comorbid & FGSI score $(\%)$ & & $\mathrm{p}$ \\
\cline { 2 - 3 } & $<9$ & More than 9 & \\
\hline DM & $11(55)$ & $9(45)$ & 0.036 \\
Non DM & $12(100.0)$ & $0(0.0)$ & \\
\hline FGS: Foun & &
\end{tabular}

Statistical test using the chi-square technique resulted in the number $p=0.036$. In other words, it can be concluded that there is a significant relationship between the DM comorbid and the FGSI score.

\section{Discussion}

This retrospective study showed the distribution of $\mathrm{FG}$ patients based on age, most were aged 50-59 years with 9 patients (50\%), 60-69 years old, 4 patients $(22.22 \%),<50$ years old, and $70-70$ years old. 79 years with a total of 2 patients $(11.11 \%)$ and more than 80 years, 1 patient $(5.56 \%)$. Most of the ages of FG occurred at the age of $50-59$ years with an average patient age of 60.5 years. This is consistent with some literature, which states that the peak incidence of FG is at the age of 5 and 6 years of age [9], [12], [13].

Old age is susceptible to FG because the immune system is starting to weaken and awareness of personal hygiene is low, so that local infections in a place, especially the urogenital area can become entry point spread of FG. Men aged 5 and 6 years also often receive invasive procedures in the field of urology, for example, insertion of catheters due to urinary retention due to prostate enlargement Benign Prostate Hyperplasia. The ages of 5 and 6 years are also often neglected sociocultural, so that the diagnosis of FG is often late and increases morbidity and even mortality for patients.

The FGSI variable, however, does not place age as a parameter. The clinical, laboratory, and comorbid conditions of FG patients at diagnosis have a greater role in influencing the FGSI score, not the patient's age, however, some literature still states that older FG patients have a lower life expectancy. Age is an independent risk factor for mortality in FG patients [9], [12], [13].
This study found that FG patients with an FGSI score $<9$ were 13 patients $(72.23 \%)$, FG patients with an FGSI score of $>9$ were 5 patients $(27.78 \%)$. Judging by the distribution of the FGSI score according to the age of the FG patient using the Chi-square technique, the value $p=0.045$. The $p$-value $<0.05$ means that at the $5 \%$ significance level the difference in the proportion of FGSI scores between age categories of FG patients is significant.

This study found that there were 11 patients with FG with DM comorbid $(61.11 \%)$ while there were 7 patients with no DM comorbid (38.89\%). This is in accordance with the literature which states that the most comorbid in FG patients is DM (50$70 \%$ [1], [2], [12]. The high incidence of diabetes in FG is due to tissue ischemia process due to small blood vessel abnormalities [1], [2], [12].

The distribution of patients in this study showed that patients with DM comorbid were more likely to have an FGSI score of $>9$ than patients without DM comorbid. Statistical test using the chi-square technique resulted in the number $p=0.036$. The $p$-value $<0.05$ means that at the $5 \%$ significance level the difference in the proportion of FGSI scores between patients with and without DM comorbid is significant.

DM affects the prognostic effect of FG patients by increasing their mortality, which is in accordance with an FGSI value of $>9$ which affects the mortality of FG patients. In lethargy, it is stated that FGSI is above 9 , the probability of mortality is $75 \%$, if it is below 9 the possibility of survival is $78 \%$ with a mortality rate of $12.12 \%$ [6], [9], [11], [14], [15].

\section{Conclusion}

In this study, seen from the FGSI score statistical data, it can be concluded that there is a significant relationship between the age of the FG patient and the FGSI score and there is a significant relationship between the DM comorbid and the FGSI score.

\section{References}

1. Hohenfellner M, Santucci RA. Emergencies in Urology. Germany: Springer; 2007. p. 50-9.

2. Moslemi MK, Gilani MA, Moslemi AA, Arabshahi A. Fournier gangrene presenting in a patient with undiagnosed rectal adenocarcinoma: A case report. Cases J. 2009;2(12):9136. https://doi.org/10.1186/1757-1626-2-9136

3. Wein AJ, Schaeffer AJ, Schaeffer EM. Campbell Walsh Urology, Fournier Ganggrene. $10^{\text {th }}$ ed. Philadelphia, PA: Elsivier; 2012. 
p. 324-5, 451-3.

4. Bonkat $G$, Bartoletti R, Bruyère $F$, Cai $T$, Geerlings SE, Köves B et al. European Association of Urology Guidelines on Urological Infections, UK; 2020

5. Michael TM. Urology, Urologic Emergencies: Fournier's Ganggrene. $4^{\text {th }}$ ed. United Kingdom: Lippincott Williams and Wilkins; 2006. p. 67.

6. Verma S, Sayana A, Kala S, Rai S. Evaluation of the utility of the Fournier's Gangrene severity index in the management of Fournier's Ganggrene in North India: A multicentre retrospective study. J Cutan Aesthet Surg. 2012;5(4):273-6. https://doi. org/10.4103/0974-2077.104916

PMid:23378710

7. Reynard J, Brewster SF, Biers S, Neal NL. Oxford Handbook of Urology, Infections and Inflammatory Conditions: Fournier's Gangrene. $1^{\text {st }}$ ed. United Kingdom: Oxford Medicine; 2006. p. 162. https://doi.org/10.1093/med/9780198783480.003.0006

8. Novick AC, Gill IS, Klein EA, Rackley R, Ross JH. Operative Urology at the Cleveland Clinic: Adult Scrotal Surgery. New Jersey: Humana Press; 2006. p. 538-41.

9. Kim IY. Gangrene: The Prognostic Factors and Validation of Severity Index in Fournier's Ganggrene, Korea; 2011. Available from: https://www.intechopen.com/chapters/18911. [Last accessed on 2021 Aug 10].
10. Sorensen MD, Krieger JN, Rivara FP, Klein MB, Wessells H. Fournier's Gangrene: Management and mortality predictors in a population based study. J Urol. 2009;182(6):2742-7. https://doi. org/10.1016/j.juro.2009.08.050

PMid:19837424

11. Gutierrez-Ochoa K, Castillo-de Lira HH, Velázquez-Macías RF, Landa-Soler M, Robles-Scott MA. Usefulness of Fournier's Gangrene severity index: A comparative study. Rev Mex. 2010;70(1):27-30.

12. Barreda JT, Scheiding MM, Fernández CS, Campaña JM, Aguilera JR, Miranda EF, et al. Fournier gangrene. A retrospective study of 41 cases. Cir Esp. 2010;87(4):218-23. https://doi.org/10.1016/s2173-5077(10)70051-x PMid:20152961

13. Mallikarjuna MN, Vijayakumar A, Patil VS, Shivswamy BS. Fournier's Gangrene: Current practices. ISRN Surg. 2012;2012:942437. https://doi.org/10.5402/2012/942437 PMid:23251819

14. Rochmah W. Diabetes Mellitus in the Elderly, Textbook of Internal Medicine. $4^{\text {th }}$ ed. Jakarta: IPD FKUI; 2007. p. 1915-8.

15. American Diabetes Association, Standards of Medical Care in Diabetes, USA; 2010. Available from: https://care. diabetesjournals.org/content/27/suppl_1/s15. [Last accessed on 2021 Aug 10]. 